\title{
LA AUTOESTIMA DE TU HIJO
}

Marveya Villalobos Torres

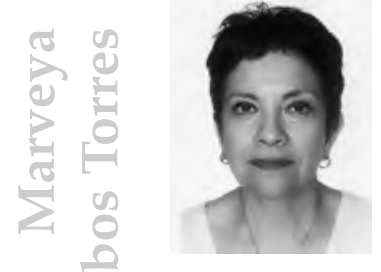

Doctora en Ciencias de la Educación, Sorbonne, Francia.

Doctora en Pedagogía, UNAM.

Maestra en Antropología Social y Cultural, Sorbonne, Francia.

Maestra en Educación Familiar, Universidad Panamericana.

Especialidad en Docencia Universitaria, UNAM.

Diplomado en Desarrollo Humano, Universidad Iberoamericana.

Licenciatura en Historia, UNAM.

Profesora Normalista y Maestra, Normal Superior, FEP.

Líneas de investigación en las áreas de Didáctica y Educación Familiar. Autora de diez obras entre las que destacan: Didáctica integrativa y el proceso de aprendizaje, Ed. Trillas; Educación Familiar. Un valor permanente, Ed. Trillas; Evaluación Institucional, Ediciones UP-Cruz.

Correo electrónico: [mvillalo@up.edu.mx].

Las personas se refieren a la autoestima como si fuera un concepto que se posee o no, y cuyos niveles indican si las personas son o no valiosas.

La autoestima es una dimensión que evalúa el concepto que la persona tiene de sí misma, sobre todo de su propio valor como persona. No es un concepto con el que se nace y se da ya por hecho, sino que va construyéndose y puede variar, dependiendo de las circunstancias por las que la persona atraviesa.

Todas las influencias recibidas por el niño son importantes, pero sobre todo las que provienen de la propia familia son fundamentales, puesto que a los hijos lo que más les significa, es ser valiosos para sus padres.

En el libro se analiza un caso práctico, ejemplificando cómo un hijo puede sentirse poco valorado por sus padres, sin que éstos lo perciban.

1 Quintanilla Madero, María Beatriz, La autoestima de tu hijo, Ed. Minos III Milenio, México, 2009, $150 \mathrm{p}$. 


\section{AUTOESTIMA}

Es la auto-evaluación global que la persona hace de sí. Se realiza sobre una escala virtual que va desde un punto positivo (auto-afirmación) hasta un punto negativo (auto-denigración). Entre el punto más alto y el más bajo existen muchas posibilidades. Por tanto, la autoestima no es un fenómeno del «todo o nada».

Refleja el estado emocional y la sensación de bienestar y de seguridad que la persona percibe sobre sí en un momento determinado. Ayuda a que ella sea más asertiva y promueva buenas relaciones interpersonales con pocos conflictos.

Sentirse apoyado y querido como uno es —y no como los demás desearían que fuésemos-, representa un factor esencial para el desarrollo de una buena autoestima.

Los hijos buscan satisfacer las expectativas que creen que sus padres tienen de ellos, aunque a veces los padres no las expongan explícitamente: copian sus actitudes y modos de comportamiento, aunque los padres no intenten que los hijos los imiten. Por ello, las órdenes verbales deben acompañarse de una congruencia de vida, de un buen testimonio en los comportamientos paternos.

La autoestima puede ser explícita o implícita. La explícita se refiere a lo que decimos de nosotros mismos y depende más de las circunstancias externas. La implícita es una forma de procedimiento automático, intuitivo, del cual no estamos conscientes.

\section{DESARROLLO CONTEMPORÁNEO DEL CONCEPTO DE AUTOESTIMA}

El actual concepto hunde sus raíces en cinco ideas: aceptación, evaluación, comparación, competencia y eficacia, y es en realidad un constructor social más que una dimensión natural de la persona. Antes no se conocía ni se utilizaba, sin embargo, con el desarrollo de nuevas ideas y formas 
de enseñar, y un mejor conocimiento de la psicología humana, se ha estudiado que la autoestima es un concepto que engloba dimensiones y aspectos personales más amplios.

Aceptación. Todos los seres humanos tenemos la necesidad de sentirnos aceptados. El primer grupo al que pertenecemos es la familia y los más afectados en este ámbito suelen ser los hijos. Ser aceptados por los demás es uno de los aspectos que más le importan a la persona, incluso en mayor medida que obtener altos logros en otras áreas de su vida.

Evaluación. Si el grupo ha establecido unas reglas, espera de cada miembro que se comporte de acuerdo a estos valores. Es por ello que según las expectativas que el grupo posee, existirá una evaluación positiva o negativa sobre los logros de cada miembro.

Comparación. Las comparaciones las encontramos en todo tipo de grupos sociales. Paradójicamente, a la vez coexiste una ideología de igualdad: la gente quiere auto-convencerse de que, como todos son «iguales», deben ser capaces de obtener lo mismo, puesto que todos tienen derecho a las mismas oportunidades.

Competencia. Cuando la persona se apoya especialmente en la competencia para aumentar su autoestima, experimenta una gran necesidad de tener control sobre los demás y su actitud es muy crítica hacia sí mismo

Eficacia. Se espera que las personas consigan las metas que el grupo le impone, y que además las realice de forma eficaz. Cuando una persona tiene problemas para lograr rápidamente las metas, puede ser evaluado como poco eficaz o como «difícil y conflictivo».

\section{EL DESARROLLO DE LA AUTOESTIMA Y DE OTRAS EMOCIONES}

La autoestima es una dimensión que puede medirse para obtener una valoración entre dos posiciones extremas: muy alta o muy baja. La 
autoestima es una emoción o sentimiento que se aprende a reconocer y una meta a conseguir durante el desarrollo del niño.

Las emociones básicas son expresadas casi de la misma forma en todas las culturas. La autoestima es un sentimiento complejo que el niño aprende a reconocer y nombrar.

\section{FUENTES DE LA AUTOESTIMA}

La autoestima se nutre de cinco fuentes principales: la relación del niño con los padres y otras figuras significativas; las capacidades motoras e intelectuales; su progreso intelectual; su competencia social, y las actitudes de la comunidad hacia ellos.

\section{LA INTERPRETACIÓN DE LOS SENTIMIENTOS}

La autoestima puede surgir como una respuesta «natural» en determinadas circunstancias sociales, especialmente cuando el niño obtiene la aprobación de sus padres por lo realizado.

Se encuentra dentro de los sentimientos sociales construidos, o mejor dicho, el significado que tiene al experimentar dicha emoción ante determinadas situaciones.

\section{EL ESTADO DE ÁNIMO Y LA AUTOESTIMA}

La persona no es indiferente ante sus emociones ni ante sus estados de ánimo. La autoestima responde a la necesidad cultural de interpretar el estado de ánimo personal en relación con aquello que la sociedad y la cultura esperan de la persona.

Un estado de ánimo positivo y regular es fundamental en el desarrollo de las capacidades para encontrar y percibir las virtudes de los demás, además ayuda a enfrentar los problemas, a estar alegre, y a comprender y a perdonar a los demás. 


\section{PELIGROS RELACIONADOS CON UN ALTA AUTOESTIMA}

- Vanidad.

- Búsqueda de autosatisfacción.

- Amor injustificado.

- Egoísmo.

- Jactancia.

- Narcisismo.

\section{DIMENSIONES DEL BIENESTAR}

Son aquellas dimensiones que contribuyen a que la persona pueda alcanzar una «vida buena». Se pueden medir de manera global y a través de lo que la propia persona percibe de modo subjetivo.

Las seis dimensiones propuestas por Ryff y Singer son:

1. Auto-aceptación.

2. Relaciones positivas con los demás.

3. Autonomía.

4. Dominio sobre el entorno.

5. Propósito en la vida.

6. Crecimiento personal.

Los seis niveles que determinan el bienestar subjetivo, según Sheldon, son:

a. Satisfacción de las necesidades.

b. Rasgos de la personalidad.

c. Metas e intenciones (específicamente metas positivas).

d. El yo y los sentimientos hacia el yo.

e. Soporte social.

f. Cultura. 


\section{SITUACIONES ESPECIALES}

\section{QUE PUEDEN AFECTAR LA AUTOESTIMA}

- Niños con trastornos por déficit de atención con hiperactividad (TDAH).

- Niños con un padre autoritario o a una madre dominante.

- Enfermedades que incapacitan a la persona para ser autosuficiente e independiente.

- Experiencias traumáticas y abuso psicológico o sexual, especialmente en la infancia.

- En el adulto, pérdida paulatina de autoridad, autonomía e independencia al envejecer.

Elvia Marveya Villalobos Torres 